УДК 631.4

doi: $10.31251 /$ pos.v4i2.146

\title{
ПРОСТРАНСТВЕННОЕ РАСПРЕДЕЛЕНИЕ ТЕМПЕРАТУРЫ ПОЧВ В КОМПЛЕКСНОМ ПОЧВЕННОМ ПОКРОВЕ ПРЕДСАЛАИРЬЯ
}

\author{
(C) 2021 Н.А. Шапорина, Е.А. Сайб
}

Адрес: ФГБУН Институт почвоведения и агрохимии СО РАН, проспект Академика Лаврентьева, 8/2, 2. Новосибирск, 630090, Россия. E-mail: sajb@issa-siberia.ru

\begin{abstract}
Цель исследования: проследить закономерность распределения температуры почв по профилю 6 условиях склоновых территорий (Предсалаирье). Для достижения иели были поставлены следуюшие задачи: оченка температурного режима почв Предсалаирья, находящихся в сельскохозяйственном использовании; изучение закономерностей изменения температуры в течение суток и выявление возможной взаимосвязи с почвенно-физическими свойствами исследуемых участков; выявление зависимости формирования температурного поля от почвенных свойств.
\end{abstract}

Место и время проведения. Исследования проводились в лесостепной зоне, в пределах Буготакского мелкосопочника $\left(55^{\circ} 03^{\prime}\right.$ с.и.; $88^{\circ} 50^{\prime}$ в.д.). Объектом исследования стал ряд почв выпуклого склона (длина 411 м) юго-восточной экспозиции. Было заложено пять полнопрофильных разрезов, недалеко от которых были установлены автономные температурные датчики (DS-1921G «Thermochron») через каждые 5 см до глубины 50 см, фиксирующие температуру каждые полчаса. Период наблюдения - с 1 июля по 15 августа 2016 года.

Основные результаты. Температурное поле пахотных почв склоновых поверхностей Предсалаирья является латерально неоднородным. Исследования показали, что пространственная изменчивость таких показателей, как влажность и плотность почв, в значительной степени влияет на теплопроводность почвенных горизонтов и является основной причиной неоднородности температурного поля. Рельеф, микрорельеф и экспозиция склона также играют важную роль в перераспределении влаги, неоднородности уплотнения u, соответственно, способствуют неравномерному прогреву верхних почвенных горизонтов. В наблюдениях как за суточным ходом температур в почвах при различных погодных условиях, так и за их сезонными колебаниями установлено, что расхождения в температурах сопряженных почв составляют $0,5-2{ }^{\circ} \mathrm{C}$.

Заключение. Температурный режим почв является определяющчим фактором функиионирования агроэкосистем, от которого зависит интенсивность протекания больиинства процессов в почвах. Исследования, основанные на количественных оценках интенсивности внутрипочвенных процессов при различной температуре, становятся всё более востребованы в самых разных областях, особенно при прогнозировании развития эрозионных процессов, или, например, при регулировании продукиионного проиесса сельскохозяйственных экосистем. А как показало данное исследование, температурный режим почв даже в пределах одного поля может значительно варьировать.

Ключевые слова: почвы, температура, влажность, плотность, микрорельеф, корреляция.

Цитирование: Шапорина Н.А., Сайб Е.А. Пространственное распределение температурь почв в комплексном почвенном покрове Предсалаирья // Почвы и окружающая среда. 2021. Том 4. № 2. е146. doi: $10.31251 /$ pos.v4i2.146

\section{ВВЕДЕНИЕ}

В настоящее время в почвоведении активно развивается структурно-функциональное направление, в основе которого лежит рассмотрение различных аспектов функционирования почвы в тесной взаимосвязи с ее строением на различных уровнях организации, в том числе на уровне почвенного покрова (Гончаров, 2010).

Температура почвы является одним из ключевых факторов, определяющих функционирование агроэкологических систем. От температурного режима сильно зависит интенсивность протекающих в почве процессов, как механических и геохимических, так и биологических (Горышина, Макаревич, 1973; Бахлаева и др., 2002; Базыкина и др., 2007; Архангельская, 2012). Химические реакции ускоряются в 2-3 раза при повышении температуры на $10{ }^{\circ} \mathrm{C}$ (правило Вант-Гоффа). От температуры зависят такие процессы, как сорбция и десорбция; растворимость газов; соотношение твердой и жидкой фаз в почве; пептизация и коагуляция коллоидов. Не менее важную роль температура играет в питании растений: растворенные питательные вещества гораздо быстрее разносятся в теплых условиях, чем в холодных. Это 
связано с тем, что повышение температуры в почве увеличивает скорость многих химических реакций, что напрямую влияет на доступность питательных веществ для растений (Христенко, Шатохина, 2002; Курганова, Типе, 2003; Parkin, Kaspar, 2003). Поэтому задача выявления закономерностей пространственного варьирования температуры почвы в масштабе сельскохозяйственного поля, количественной оценки этого варьирования и прогнозирования температурного режима почвенных разностей приобретает все большую актуальность, особенно с учетом перспектив развития точного земледелия (Кирюшин, 2010).

\section{МАТЕРИАЛЫ И МЕТОДЫ ИССЛЕДОВАНИЯ}

Территория исследования приурочена к югу Западной Сибири и находится в зоне лесостепи. Объекты исследования расположены в пределах Буготакского мелкосопочника, расположенного на правом берегу Оби. Территория характеризуется достаточно сильной расчлененностью (до 2,2 км/км²), высота над уровнем моря достигает 350 м. Объектом исследования стал ряд почв выпуклого склона (длина 411 м) юго-восточной экспозиции. Уклон исследуемой территории меняется от $6^{\circ}$ в нижней его части до $1^{\circ}$ в верхней. Большую часть (до $60 \%$ ) исследуемой территории склона составляют оподзоленные черноземы, расположенные в верхней части. Темносерые лесные почвы занимают $39 \%$ территории и располагаются в основном в средней и нижней части данного склона. Менее $1 \%$ приходится на почвы лугового типа, которые располагаются в самой нижней части склона (Хмелев, Танасиенко, 2013). Полнопрофильные почвенные разрезы были заложены на пяти площадках (рис. 1). Начиная с поверхности до глубины 50 см через каждые 5 см устанавливались автономные температурные датчики (DS-1921G «Thermochron»), запрограммированные фиксировать температуру каждые полчаса. Датчики установлены 1 июля, сняты 15 августа.

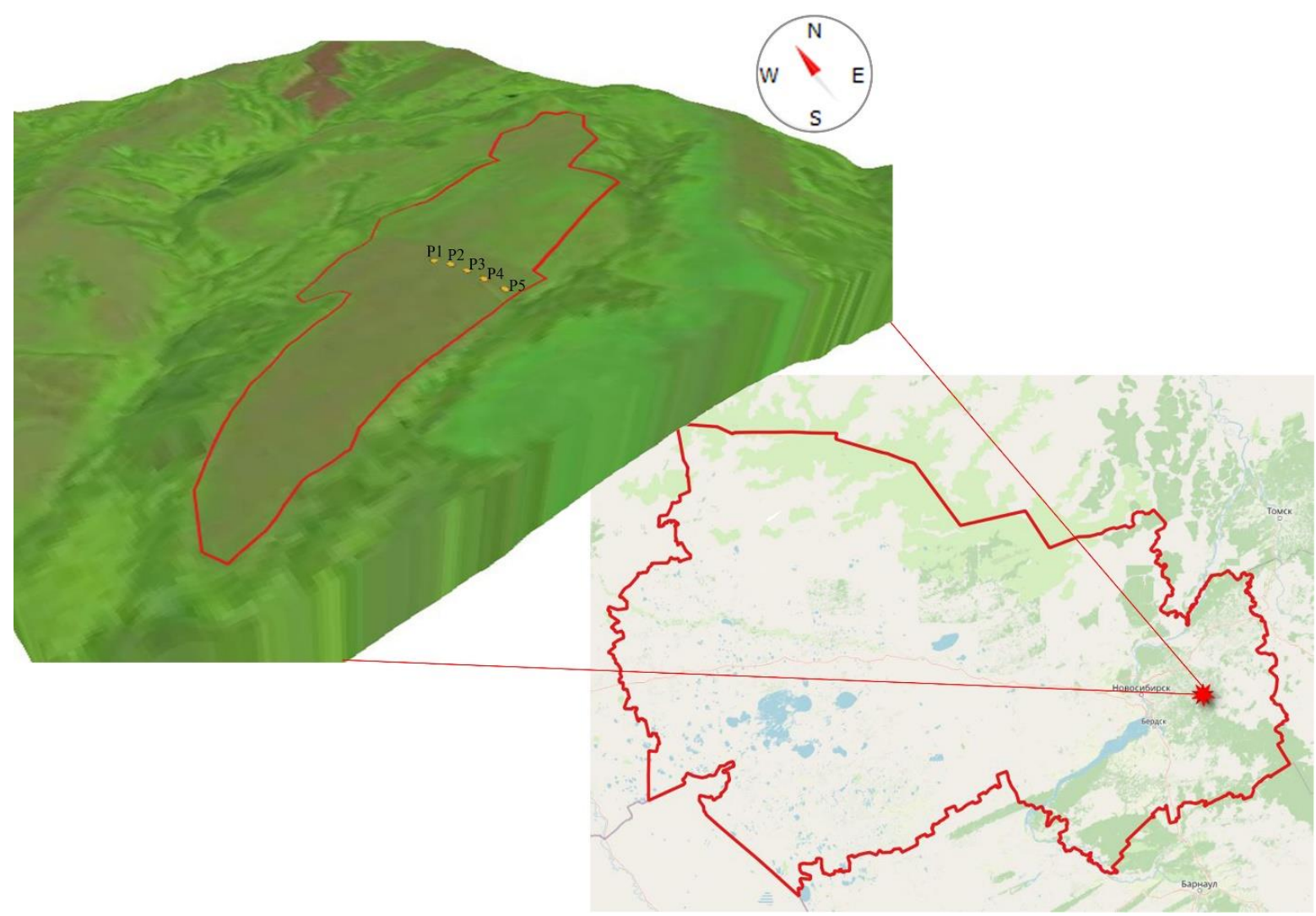

Рисунок 1. Район исследования и расположение разрезов на склоне.

Почвы: Р1 - чернозем оподзоленный неэродированный; Р2 - чернозем оподзоленный слабоэродированный; Р3 - темно-серая лесная слабоэродированная; Р4 - чернозем оподзоленный сильноэродированный; Р5 - луговая средненамытая.

Образцы на влажность отбирали один раз в 10 дней буром через 10 см до глубины 50 см в трехкратной повторности, также в период с 1 июля по 15 августа. Почвенную влажность 
определяли термостатно-весовым методом. В этот же период проводили мониторинг погодных условий (отслеживали температуру воздуха и осадки).

\section{РЕЗУЛЬТАТЫ ИССЛЕДОВАНИЯ И ИХ ОБСУЖДЕНИЕ}

Основными почвенными параметрами, влияющими на формирование температурного режима, являются влагосодержание и плотность почв. Исходя из этого, изучено пространственное распределение этих почвенных свойств, характеризующих функционирование почвы. Результаты исследований показали неоднородность агрофизических свойств изучаемых почв. Так, например, наибольшей плотностью пахотного горизонта отличались неэродированный чернозем оподзоленный и луговая намытая почва. Но подпахотный горизонт последней отличался неравномерностью уплотнения от $1,21 \mathrm{r} / \mathrm{cm}^{3}$ до 1,40 г/ $\mathrm{cm}^{3}$, что свидетельствует о своеобразии формирования профиля намытых почв (табл. 1). Для почвы средней части склона (темно-серая лесная слабоэродированная) характерна относительная рыхлость пахотного горизонта $(1,15-1,21$

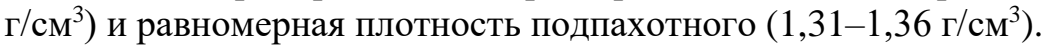

Таблица 1

Плотность деятельного слоя эродированных почв Предсалаирья, г/см³ (июль 2016 года)

\begin{tabular}{|c|c|c|c|c|c|}
\hline Слой, см & $\begin{array}{c}\text { Чернозем } \\
\text { оподзоленный } \\
\text { неэродированный }\end{array}$ & $\begin{array}{c}\text { Чернозем } \\
\text { оподзоленный } \\
\text { слабоэродиро- } \\
\text { ванный }\end{array}$ & $\begin{array}{c}\text { Серая лесная } \\
\text { слабоэродиро- } \\
\text { ванная почва }\end{array}$ & $\begin{array}{c}\text { Чернозем } \\
\text { оподзоленный } \\
\text { сильноэродиро- } \\
\text { ванный }\end{array}$ & $\begin{array}{c}\text { Луговая } \\
\text { средненамытая } \\
\text { почва }\end{array}$ \\
\hline $0-10$ & 1,24 & 1,14 & 1,04 & 1,07 & 1,30 \\
\hline $10-20$ & 1,23 & 1,29 & 1,25 & 1,24 & 1,30 \\
\hline $\begin{array}{l}\text { Среднее в } \\
\text { пахотном } \\
\text { гопизонте }\end{array}$ & 1,24 & 1,21 & 1,15 & 1,15 & 1,30 \\
\hline $20-30$ & 1,29 & 1,32 & 1,25 & 1,32 & 1,21 \\
\hline $30-40$ & 1,44 & 1,35 & 1,34 & 1,37 & 1,40 \\
\hline $40-50$ & 1,42 & 1,42 & 1,32 & 1,32 & 1,31 \\
\hline $\begin{array}{c}\text { Среднее в } \\
\text { подпахотном } \\
\text { горизонте }\end{array}$ & 1,38 & 1,36 & 1,31 & 1,34 & 1,31 \\
\hline $\begin{array}{c}\text { Среднее в слое } \\
0-50 \text { см }\end{array}$ & 1,31 & 1,28 & 1,23 & 1,25 & 1,30 \\
\hline
\end{tabular}

Степень увлажнения почв в указанный период характеризовалась изменчивостью, обусловленной непостоянством погодных условий. В начале периода наблюдений 50 -см слой практически у всех исследуемых типов почв был иссушен почти одинаково - до 62-64\% от наименьшей влагоемкости (НB), и только у луговой средненамытой почвы увлажнение было немного выше - около 70\% НВ. Стоит заметить, что более высокий уровень увлажнения (> НВ) в профиле этой почвы отмечался в течение всего периода наблюдений.

Осадки выпадали неравномерно. Все 55 мм выпавших в первой декаде осадков остались в наблюдаемой толще всех почв. Наличие гравитационной влаги 10 июля было зафиксировано только в луговой средненамытой почве (20 мм). В период с 27 июля по 15 августа осадков практически не было, поэтому отмечался активный расход влаги во всех исследуемых почвах. К концу периода наблюдений черноземы содержали в среднем 70\% влаги от НВ, темно-серая лесная и луговая средненамытая - 83 и $88 \%$ от НВ соответственно.

Установка регистраторов «Thermochron» позволила получить достаточно репрезентативную выборку данных по температуре для трех почв, наиболее контрастных по свойствам на уровне 
типа: чернозема оподзоленного неэродированного, серой лесной слабоэродированной и луговой средненамытой (рис. 2).

Для всех типов почв фиксируются устойчивые тренды снижения температуры почвы за наблюдаемый период. Однако наклоны линий тренда отличаются. В серых лесных почвах и в луговых намытых наклон заметно больше, что означает более сильную тенденцию снижения температуры за один и тот же период времени. Тенденция сохраняется на глубине 20 см.

1

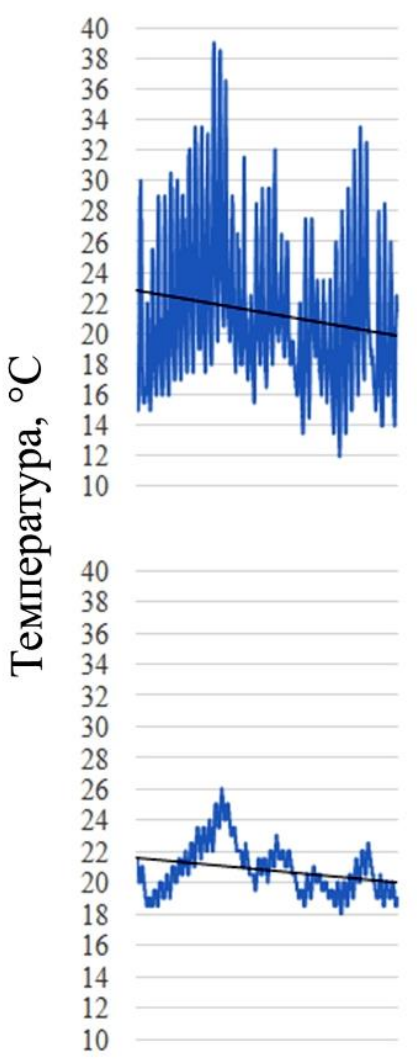

2

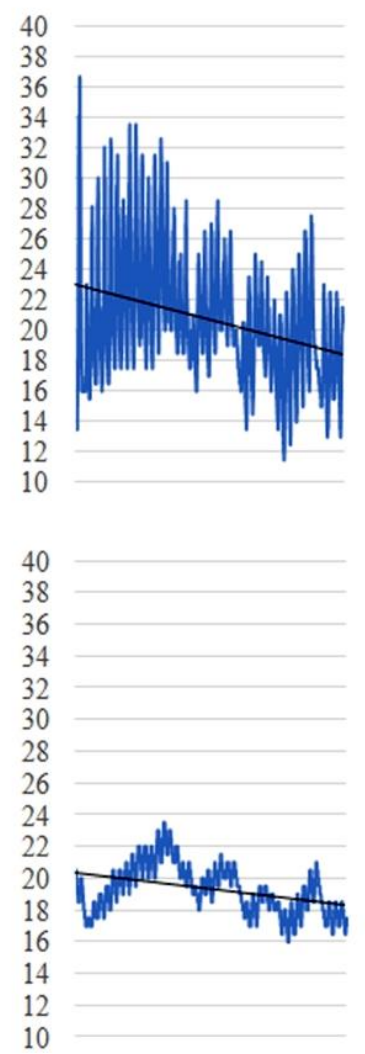

3

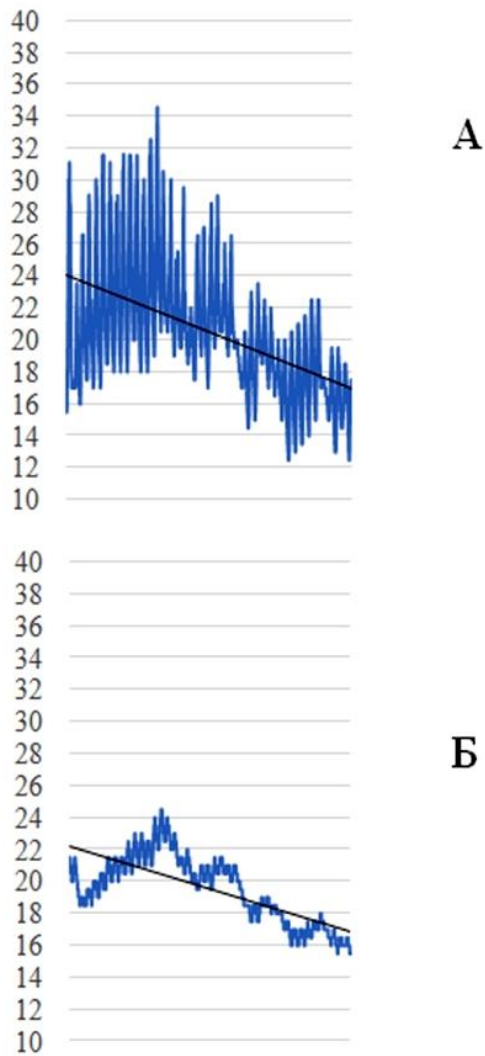

Рисунок 2. Динамика температуры в почвах Предсалаирья за весь цикл наблюдений.

А - на поверхности, Б - на глубине 20 см; почвы: 1 - чернозем оподзоленный неэродированный, 2 - серая лесная слобоэродированная, 3 - луговая средненамытая.

Статистическая обработка данных представлена в таблице 2. Средние температуры поверхности чернозема самые высокие $-21,4{ }^{\circ} \mathrm{C}$, поверхность серой лесной почвы в среднем на $0,7^{\circ} \mathrm{C}$, луговой намытой - на $0,9^{\circ} \mathrm{C}$ холоднее. Та же тенденция сохраняется и на глубинах 20 и 50 см. На глубине 50 см разница между черноземом и луговой намытой почвой достигает $1,3{ }^{\circ} \mathrm{C}$. Размах колебаний между дневными и ночными температурами на поверхности также закономерно снижается от чернозема до луговой намытой почвы: 27,25 и $22{ }^{\circ} \mathrm{C}$ соответственно, что связано с различным увлажнением поверхности. Однако на глубине 20 см закономерность нарушается: наибольший размах - в луговой намытой почве. Также в этой почве на глубине 20 см более высокое стандартное отклонение и коэффициент вариации. Причина может быть в особенностях сложения почвенного профиля, например, в неравномерном уплотнении, так как прослойки более низкой плотности обладают значительно меньшей температуропроводностью и способны замедлять прогрев нижележащих горизонтов. Кроме того, луговая средненамытая почва обладает мощной гумусовой толщей, и к тому же (в данном случае) расположена в нижней части склона, что способствует накоплению большего количества влаги и, соответственно, развитию более высокого травостоя, что, в свою очередь, также снижает возможность прогревания почвы. Черноземы оподзоленные, расположенные на плакоре, являются более плотными и равномерно сложенными, и, соответственно, они значительно теплее. Вариабельность температуры на 
поверхности всех почв высокая (20-23\%) и резко снижается (до 4,4-6,6\%) на глубине 50 см, что свидетельствует о более ровном увлажнении профиля.

Таблица 2

Статистические показатели температурного режима почв Предсалаирья

\begin{tabular}{|c|c|c|c|c|c|c|c|c|c|}
\hline \multirow{2}{*}{ Показатель } & \multicolumn{3}{|c|}{$\begin{array}{c}\text { Чернозем оподзоленный } \\
\text { неэродированный }\end{array}$} & \multicolumn{3}{c|}{$\begin{array}{c}\text { Серая лесная } \\
\text { слабоэродированная почва }\end{array}$} & \multicolumn{3}{c|}{ Луговая средненамытая } \\
\cline { 2 - 10 } & Поверхность & $20 \mathrm{~cm}$ & $50 \mathrm{~cm}$ & Поверхность & $20 \mathrm{cм}$ & $50 \mathrm{~cm}$ & Поверхность & 20 см & 50 см \\
\hline Среднее & 21,4 & 20,8 & 18,8 & 20,7 & 19,3 & 18,4 & 20,5 & 19,5 & 17,4 \\
\hline Максимум & 39,0 & 26,0 & 21,0 & 36,5 & 23,5 & 20,0 & 34,5 & 24,5 & 19,5 \\
\hline Минимум & 12,0 & 18,0 & 17,5 & 11,5 & 16,0 & 17,0 & 12,5 & 15,5 & 15,0 \\
\hline Размах & 27,0 & 8,0 & 4,5 & 25,0 & 4,5 & 3,0 & 22,0 & 9,0 & 4,5 \\
\hline $\begin{array}{c}\text { Стандартное } \\
\text { отклонение }\end{array}$ & 4,9 & 1,6 & 0,9 & 4,2 & 1,5 & 0,8 & 4,1 & 2,1 & 1,2 \\
\hline Дисперсия & 24,0 & 2,5 & 0,7 & 17,6 & 2,3 & 0,6 & 16,0 & 4,4 & 1,3 \\
\hline $\begin{array}{c}\text { Коэффициент } \\
\text { вариации }\end{array}$ & 22,9 & 7,6 & 4,6 & 20,3 & 7,9 & 4,4 & 20,0 & 10,8 & 6,6 \\
\hline
\end{tabular}

Результаты исследования пространственного распределения средних температур представлены в виде топоизоплет (рис. 3), построенных с использованием интерполяции методом кригинга, которые наглядно демонстрируют характер распределения средних температур вдоль склона (характеристики склона см. на рис. 1). Современные возможности обработки пространственно-распределенных данных способны обеспечить количественное описание изменчивости почвенных характеристик, позволяют повысить точность оценки почвенных свойств при интерполяции данных и являются основой для планирования рационального отбора почвенных проб (Дмитриев, 1995; Сидорова, 2011).

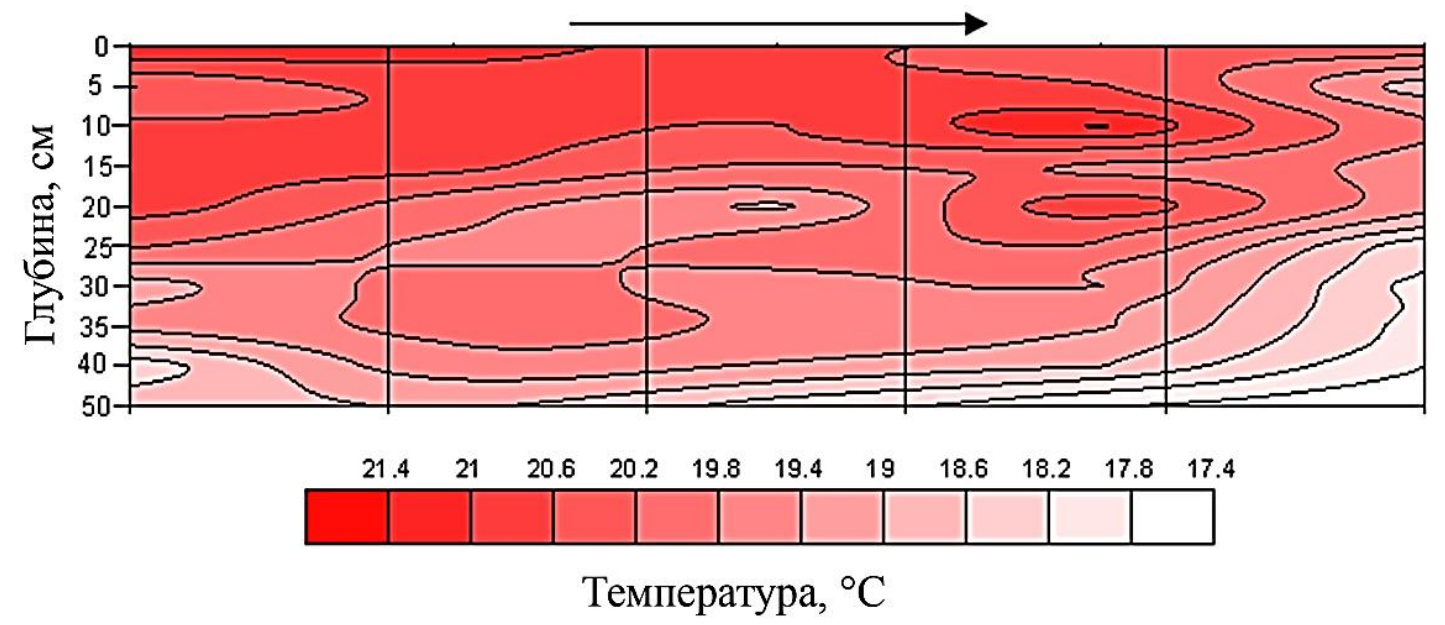

Рисунок 3. Распределение среднесуточных температур профиля глубиной 50 см по трансекте вдоль склона ( $\rightarrow-$ направление уклона).

Для наглядного представления различий суточного хода температур в почвах было выбрано два периода по 5 дней, различных по метеорологическим условиям. Первый, с 5 по 10 июля, был жарким и влажным; средняя температура воздуха составила $20,9{ }^{\circ} \mathrm{C}$, максимальная $-28,1{ }^{\circ} \mathrm{C}$, минимальная $-14,6^{\circ} \mathrm{C}$; выпадали обильные осадки. Второй, с 5 по 10 августа, был теплым и сухим, со средней температурой воздуха $18,7{ }^{\circ} \mathrm{C}$, без осадков. Ночная температура воздуха снижалась до $10^{\circ} \mathrm{C}$. Суточные колебания температуры были зафиксированы до глубины 35 см, на глубине 40 см они были едва заметны, на глубине 50 см не наблюдались (Шапорина и др., 2016). 
Статистические показатели суточного хода температур в трех почвах, наиболее контрастных по влажностному режиму, представлены на рис. 4.

A
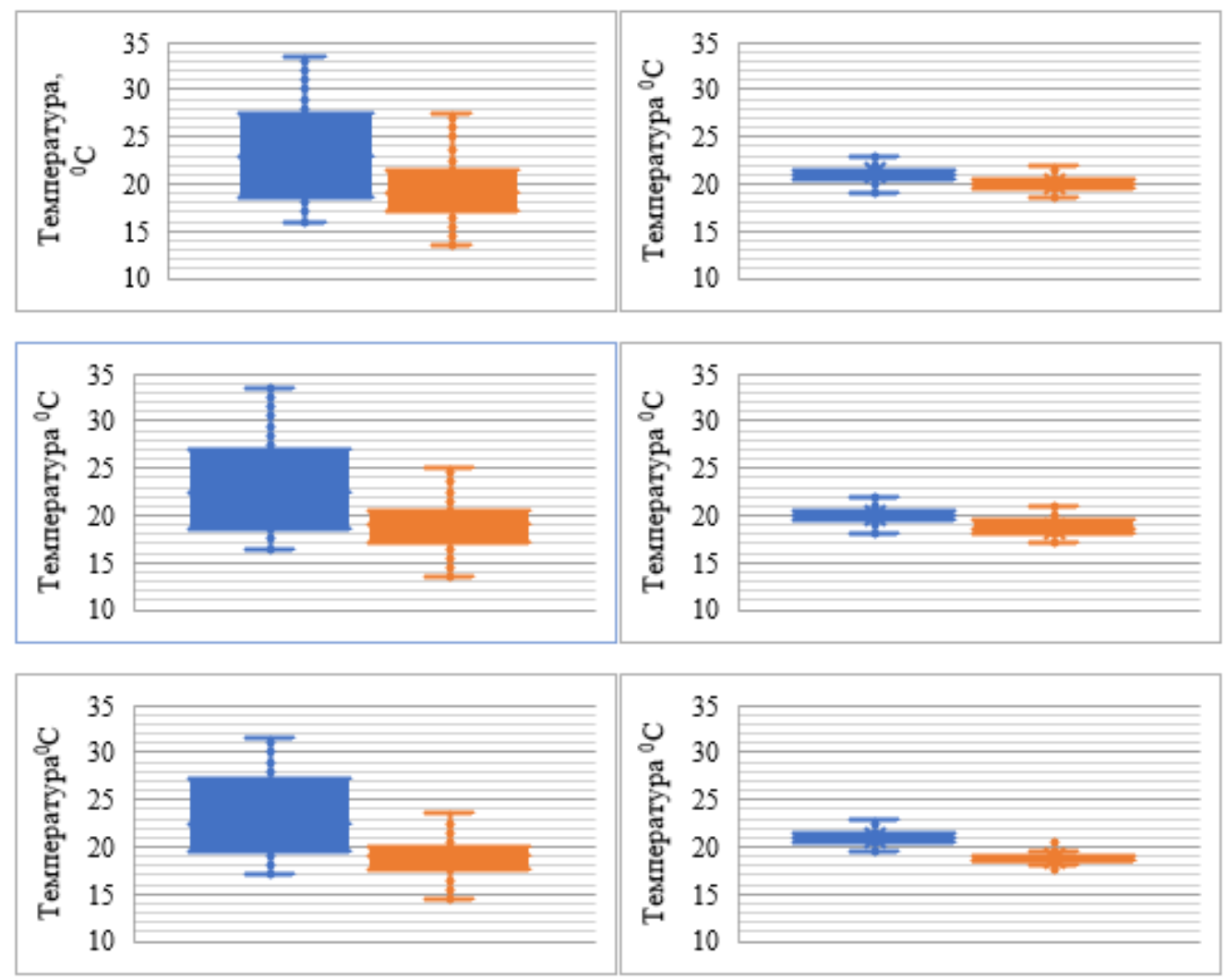

1

2

3

Рисунок 4. Статистические показатели варьирования значений суточного хода температуры почв на поверхности (А) и на глубине 20 см (Б).

Почва: 1 - чернозем оподзоленный неэродированный; 2 - темно-серая лесная слабоэродированная; 3 - луговая средненамытая (2016 год, июль - август).

Период наблюдений: $\square-$ c 5 по 10 июля; $\square$ - с 5 по 10 августа.

В обоих периодах наблюдений отмечались устойчивые тренды: в первом температура повышалась, а во втором снижалась. В первом размах колебаний дневных и ночных температур на поверхности почвы составил в среднем $15{ }^{\circ} \mathrm{C}$, на глубине $20 \mathrm{~cm}-4{ }^{\circ} \mathrm{C}$. Выпадение обильных осадков привело к значительному уменьшению теплового потока и снижению размаха колебаний до $11{ }^{\circ} \mathrm{C}$. Во втором периоде наблюдалась совершенно другая картина: размах колебаний между дневными и ночными температурами не превышал $4-6{ }^{\circ} \mathrm{C}$, при этом среднесуточные температуры снижались.

Почвенные разности можно четко разграничить по температурному режиму. Например, поверхностный слой чернозема оподзоленного оказался на $6{ }^{\circ} \mathrm{C}$ теплее, чем серой лесной слабоэродированной почвы, а луговой намытой и вовсе на $8{ }^{\circ} \mathrm{C}$. На глубине 20 см серая лесная слабоэродированная почва на $2{ }^{\circ} \mathrm{C}$, а луговая намытая на $4{ }^{\circ} \mathrm{C}$ холоднее чернозема оподзоленного неэродированного. Это можно объяснить тем, что в первом (влажном) периоде все эти почвы имеют относительно одинаковую степень увлажнения.

В отсутствие осадков во втором периоде расход влаги на транспирацию и испарение шел поразному из-за приуроченности разных почв к различным элементам рельефа и микрорельефа (черноземы в основном занимают плакорные участки, серые лесные преимущественно тяготеют к микрозападинам, луговые намытые расположены в самой нижней части мезосклона). На перераспределение влаги по склону влияет не только направление и крутизна основного мезосклона, не меньшее влияние оказывает микрорельеф склоновой поверхности. Установлено, что в местах выделенных микрозападин повышенное увлажнение профиля наблюдается даже в условиях засушливых периодов. К подобным выводам пришел А. П. Сорокин (2009), в своей 
работе он выявил корреляционные зависимости между почвенными свойствами и рельефом. Наши исследования в Предсалаирье показали, что коэффициент корреляции увлажненности почв с микрорельефом составляет 0,69. Ранее проведенные исследования в Приобье на черноземах также показали, что латеральная неоднородность пахотного горизонта по значениям плотности и влажности сказывается и на его температурных показателях. Анализ средних значений теплофизических коэффициентов генетических горизонтов для черноземов (за весь вегетационный период) показал, что более высокая влажность способствует меньшему дневному прогреву верхних горизонтов (примерно до 50 см), и, соответственно, получению более низких значений среднесуточных температур (Шапорина, Чичулин, 2017).

\section{ЗАКЛЮЧЕНИЕ}

Показано, что склоновая поверхность по почвенным свойствам является в значительной степени пространственно неоднородной. Крутизна склона, его протяженность, перепады высот и даже микрорельеф являются определяющими факторами в распределении влаги в почвах. Между влажностью поверхностного слоя 0-10 см и микрорельефом выявлены тесные корреляционные связи (коэффициент корреляции составил 0,69). На пространственную изменчивость плотности почвы основное влияние оказывают морфологические особенности строения профиля. Температурное поле пахотных почв, почвенного покрова склоновых поверхностей Предсалаирья в силу изменчивости влажности и плотности также является латерально неоднородным. Неоднородность температурного поля в почвенном покрове объясняется отличиями в физических свойствах почвенных горизонтов, в первую очередь их температуропроводности.

Наблюдение как за суточным ходом температур в почвах, так и за их сезонными колебаниями в разных погодных условиях показало, что расхождение температур в сопряженных почвах составляет $0,5-2{ }^{\circ} \mathrm{C}$. В течение вегетационного периода почвы средней и нижней частей склона (серые лесные различной степени эродированности и луговые намытые почвы), в отличие от черноземов плакоров, характеризуются более низкой температурой, особенно в подпахотном горизонте.

Исследования, основанные на количественных оценках интенсивности протекания различных внутрипочвенных процессов при различной температуре, становятся всё более востребованы в самых разных областях, особенно при прогнозировании развития эрозионных процессов или, например, при регулировании продукционного процесса сельскохозяйственных экосистем.

\section{ФИНАНСОВАЯ ПОДДЕРЖКА}

Работа выполнена по государственному заданию ИПА СО РАН в рамках программы, финансируемой Министерством науки и высшего образования Российской Федерации.

\section{ЛИТЕРАТУРА}

1. Архангельская Т. А. Температурный режим комплексного почвенного покрова. М: Изд-во ГЕОС, 2012. $282 \mathrm{c}$.

2. Базыкина Г. С., Скворияова Е. Б., Тонконогов В. Д., Хохлов С. Ф. Влияние составляющих водного баланса и температурного режима на свойства постагрогенных дерново-подзолистых почв Подмосковья // Почвоведение. 2007. № 6. С. 685-697.

3. Бахлаева О. С., Никольский Ю. Н., Контрерас-Бенитес А., Ордас-Чапарро В. Оценка изменений свойств почв в зависимости от гидротермических условий на сельскохозяйственных угодьях (на примере Мексики) // Почвоведение. 2002. № 10. С. 1165-1170.

4. Гончаров В. М. Агрофизическая характеристика почв в комплексном почвенном покрове. Автореф. дис... д. б. н. М., 2010. 45 с.

5. Горышина Н.Г., Макаревич В.Н. Влияние термического режима почв на ход вегетации и продуктивность некоторых луговых сообществ // Труды ГГО. 1973. Bыл. 306. C. 46-50.

6. Дмитриев Е. А. Математическая статистика в почвоведении: учебник. М.: Изд-во МГУ, 1995.320 с.

7. Кирюшин В. И. Теория адаптивно-ландшафтного земледелия и проектирование агроландшафтов. М.: Колос, 2010. 422 с.

8. К Курганова И. Н., Типе Р. Влияние процессов замерзания-оттаивания на дыхательную активность почв // Почвоведение. 2003. № 9. С. 1095-1105.

9. Сидорова В. А. Геостатистический анализ пространственной неоднородности сельскохозяйственных полей для целей точного земледелия. Автореф. дис...к. с. -х. н. Петрозаводск, 2011. $26 \mathrm{c}$. 
10. Сорокин А. П. Особенности пространственной вариабельности почвенных свойств в ландмафтах дельты Волги. Автореф. дис...к. б. н. Астрахань, 2009. 21 с.

11. Хмелев В. А., Танасиенко А. А. Почвенные ресурсы Кемеровской области и пути их рационального использования. Новосибирск: Изд-во СО РАН, 2013. 477 с.

12. Христенко С. И., Шатохина С. Ф. Влияние гидротермических факторов на микробный комплекс оподзоленного чернозема // Почвоведение. 2002. № 3. С. 335-339.

13. Шапорина Н. А., Чичулин А. В., Танасиенко А. А. Латеральная изменчивость агрофизических показателей и неоднородность гидротермического поля в почвенном покрове склоновых поверхностей Предсалаирья // Международный журнал прикладных и фундаментальных исследований. 2016. № 12-7. С. 1270-1275. https://applied-research.ru/ru/article/view?id=11027

14. Шапорина Н. А., Чичулин А. В. Влияние микрорельефа на формирование гидротермического поля почвенного покрова водоразделов Приобского плато в орошаемых условиях // Международный журнал прикладных и фундаментальных исследований. 2017. № $9 . \quad$ C. 130-134. https://appliedresearch.ru/ru/article/view?id=11841

15. Parkin T. V., Kaspar T. C. Temperature controls on diurnal carbon dioxide flux: implications for estimating soil carbon loss // Soil Sci. Soc. Am. J. 2003. Vol. 67. P. 1763-1772.

Поступила в редакциию 06.07.2021

Принята 28.09.2021

Опубликована 14.10.2021

\title{
Сведения об авторах:
}

Шапорина Нина Аркадьевна - кандидат биологических наук, старший научный сотрудник лаборатории почвенно-физических процессов ФГБУН Института почвоведения и агрохимии СО РАН (Новосибирск, Россия); shaporina@issa-siberia.ru

Сайб Екатерина Александровна - младший научный сотрудник лаборатории почвеннофизических процессов ФГБУН Института почвоведения и агрохимии СО РАН (Новосибирск, Россия); $\underline{\text { ajb @issa-siberia.ru }}$

Авторы прочитали и одобрили окончательный вариант рукописи.

(с)) हү Статья доступна по лицензии Creative Commons Attribution 4.0 License

\section{SPATIAL DISTRIBUTION OF SOIL TEMPERATURE IN THE COMPLEX SOIL COVER IN THE CIS-SALAIR REGION}

\author{
(C) 2021 N. A. Shaporina, E.A. Sayb
}

Address: Institute of Soil Science and Agrochemistry of the Siberian Branch of the Russian Academy of Sciences, Novosibirsk, Russia.E-mail: redactor@mail.ru

The aim of the study was to find out the regularity of soil temperature distribution along soil profiles located on the slope territories (Cis-Salair region, Russia). To achieve this goal, the following tasks were set: assessment of the temperature regime of the soils of the Cis-Salair region, which are in agricultural use; studying the regularities of diurnal temperature changes and identifying a possible relationship with the soil physical properties of the studied areas; revealing the dependence of the temperature field formation on soil properties.

Location and time of the study. The study was conducted in the forest-steppe zone in the Bugotak Hills in the Novosibirsk region, Russia $\left(55^{\circ} 03^{\prime} \mathrm{N} ; 88^{\circ} 50^{\prime} \mathrm{E}\right)$. The object of the study was a series of soils on a convex hillslope (411 m long) of southeastern exposure. Five soil profile pits were dug, not far from which autonomous temperature sensors (DS-1921G "Thermochron") were installed at every $5 \mathrm{~cm}$ to a depth of 50 $\mathrm{cm}$, recording the temperature every 30 minutes. The observation period was from July 1 to August 15, 2016.

Main results. The temperature field of the arable soils on the Cis-Salair slopes was laterally inhomogeneous. Our study showed that the spatial variability of such indicators as soil moisture and density significantly affected the thermal conductivity of soil horizons, which was the main reason for the temperature field heterogeneity. The relief, microrelief and slope exposition also played an important role in the redistribution of moisture, heterogeneity of the density of soil cover, and, consequently, contributed to uneven heating of the upper soil horizons. The observation of both the diurnal variation of soil temperatures under various weather 
conditions and their seasonal fluctuations found that the temperature differences in the adjacent soil series of the convex slope were $0.5-2{ }^{\circ} \mathrm{C}$.

Conclusions. Soil temperature regime is a driving factor in the functioning of agroecosystems, determining the intensity of various soil processes. Studies based on the quantitative estimates of the intensity of subsurface processes at different temperatures are becoming increasingly in demand in various fields, especially in predicting erosion development, or, for example, in regulating the production process in agricultural ecosystems. Significant variation of soil temperature regime even within the one field should be taken into consideration for planning land use and adjusting local agricultural techniques.

Key words: soils; soil temperature; soil density; moisture content; microrelief; correlation.

How to cite: Shaporina N.A., Saib E.A. Spatial distribution of soil temperature in the complex soil cover in the CisSalair region // The Journal of Soils and Environment. 2021. 4(2). e146. doi:10.31251/pos.v4i2.146 (in Russian with English abstract).

\section{REFERENCES}

1. Arkhangelskaya T. A. Temperature regime of the complex soil cover. Moscow: GEOS publ., 2012. 282 p. (in Russian)

2. Bazykina G.S., Skvortsova E.B., Tonkonogov V.D., Khokhlov S.F. Water budget items and temperature regime of postagrogenic soddy-podzolic soils of Moscow region and their effect on the soil properties, Eurasian Soil Science. 2007, Vol. 40, No. 6. p. 616-627. (in English)

3. Bakhlaeva O. S., Nikolsky Yu. N., Kontreras-Benites A., Ordas-Chaparro V. Assessment of changes in soil properties depending on hydrothermal conditions on agricultural land (for example, Mexico), Pochvovedenie. 2002, No. 10.p. 1165-1170. (in Russian)

4. Goncharov V. M. Agrophysical characteristics of soils in a complex soil cover, Abstract of Dissertation ... Dr. of Biol. Sci. in Biology. Moscow, 2010, 45 p. (in Russian)

5. Goryshina N. G., Makarevich V. N. Influence of the thermal regime of soils on the course of vegetation and productivity of some meadow communities, Trudy GGO. 1973, Vol. 306. p. 46-50. (in Russian)

6. Dmitriev E.A. Mathematical statistics in soil science: textbook. Moscow, MSU publ., 1995, 320 p. (in Russian)

7. Kiryushin V. I. Theory of adaptive landscape agriculture and design of agricultural landscapes. Moscow: Kolos publ., 2011, 442 p. (in Russian)

8. Kurganova I. N., Tipe P. The effect of freezing-thawing processes on soil respiration activity, Eurasian Soil Science. 2003, Vol. 36, No. 9. p. 1095-1105. (in English)

9. Sidorova V. A. Geostatistical analysis of spatial heterogeneity of agricultural fields for precision farming, Abstract of Dissertation ... Cand. of Agr. Sci. Petrozavodsk, 2011, 26 p. (in Russian)

10. Sorokin A. P. Features of the spatial variability of soil properties in the landscapes of the Volga delta, Abstract of Dissertation ... Cand. of Biol. Sci. in Biology. Astrakhan, 2009, 21 p. (in Russian)

11. Khmelev V. A., Tanasienko A. A. Soil resources of the Kemerovo region and the basics of its rational use. Novosibirsk: SB RAS publ., 2013, 477 p. (in Russian)

12. Khristenko S. I., Shatohina S.F. Influence of hydrothermal factors on the microbial complex of podzolized chernozem, Pochvovedenie. 2002, No. 3. p. 335-339. (in Russian)

13. Shaporina N. A., Chichulin A. V., Tanasienko A. A. The lateral variability of agrophysical indicators and the heterogeneity of the hydrothermal field in soil cover of the slope surfaces in the Cis-Salair region, International Journal of Applied and Basic Research, 2016, No.12-7, p. 1270-1275. (in Russian) https://appliedresearch.ru/ru/article/view?id=11027

14. Shaporina N. A., Chichulin A. V. The influence of microrelief on the formation of hydrothermal fields of the soil cover of the watershed Priobskoye plateau in irrigated conditions, International Journal of Applied and Basic Research, 2017, No.9, p. 130-134. (in Russian) https://applied-research.ru/ru/article/view?id=11841

15. Parkin T.V., Kaspar T.C. Temperature controls on diurnal carbon dioxide flux: implications for estimating soil carbon loss, Soil Sci. Soc. Am. J. 2003. Vol. 67. P. 1763-1772.

Received 06.07.2021

Accepted 28.09.2021

Published 14.10.2021

\section{About the authors:}

Shaporina Nina A. - Candidate of Biological Sciences, Senior Researcher in the Laboratory of Soil Physical Processes in the Institute of Soil Science and Agrochemistry of the Siberian Branch of the Russian Academy of Sciences (Novosibirsk, Russia); shaporina@issa-siberia.ru 
Sayb Ekaterina A. - Junior Researcher in the Laboratory of Soil Physical Processes in the Institute of Soil Science and Agrochemistry of the Siberian Branch of the Russian Academy of Sciences (Novosibirsk, Russia); sajb@issa-siberia.ru

The authors read and approved the final manuscript

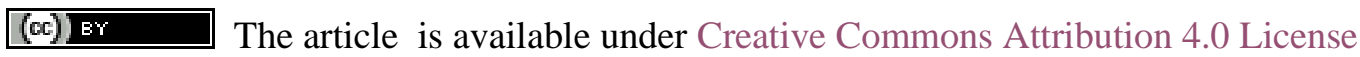

